\title{
Dynamic Influence of Near-Source Seismic Ground Motion on Underground Mine Working Stability Using Time-Frequency Analysis
}

\author{
Adam Lurka ${ }^{(D},{ }^{1}$ Grzegorz Mutke, ${ }^{2}$ and Piotr Małkowski ${ }^{3}{ }^{3}$ \\ ${ }^{1}$ Central Mining Institute (GIG) - Laboratory of Mining Geophysics, Glowny Instytut Gornictwa, 40-166 Katowice, \\ plac Gwarkow 1, Poland \\ ${ }^{2}$ Central Mining Institute (GIG)_Department of Geology and Geophysics, Glowny Instytut Gornictwa, 40-166 Katowice, \\ plac Gwarkow 1, Poland \\ ${ }^{3}$ AGH University of Science and Technology, Faculty of Civil Engineering and Resource Management, 30-059 Kraków, \\ Al. Mickiewicza 30, Poland
}

Correspondence should be addressed to Adam Lurka; alurka@gig.eu

Received 14 April 2021; Revised 18 July 2021; Accepted 24 July 2021; Published 3 August 2021

Academic Editor: Sandro Carbonari

Copyright ( 2021 Adam Lurka et al. This is an open access article distributed under the Creative Commons Attribution License, which permits unrestricted use, distribution, and reproduction in any medium, provided the original work is properly cited.

Peak particle velocity parameter is very useful in assessing underground mine working stability. Its application is widespread and requires additional analysis of the dominant frequency of the seismic signal. In order to properly analyze the velocity amplitudes of strong ground motions generated from seismic sources, time-frequency properties of near-source seismic signals in underground mines should be quantified. Using numerical calculations, the continuous wavelet transform (CWT) of the recorded near-source seismic signals in three perpendicular directions was obtained to characterize its time-frequency properties. The properties of recorded strong ground motion velocity seismograms for two high energy seismic events and two blasts from two underground coal mines in Poland have been extracted with the use of continuous wavelet transform spectrograms showing the duration time of each frequency group. Assuming a constant peak particle velocity amplitude on the analyzed seismograms, the duration time of each frequency group starts to play a key role. The longer the duration time of the lower frequency group is on the CWT spectrogram, the more the damaging effect on underground mining excavations can be observed. Varying bandwidths of dominant frequencies in separate time intervals for the analyzed seismic signals have had significantly different influence on the potentially damaging effect on underground mining excavations.

\section{Introduction}

Seismic phenomena are commonly encountered during underground mining operations. They apply to both coal mines and metal or salt ore mines. Additional dynamic stresses in the rock mass in the area of excavation caused by the seismic shock wave near the source may lead to problems with its maintenance and in the worst cases can completely damage the excavation, leading to injury or death of miners. Additionally, during mining operations, not only nearsource seismic ground vibrations should be taken into account, but also those caused by blasting work [1]. The term near-source seismic ground vibrations utilized in the whole paper is identified with seismic vibrations observed at distances of the order of few wavelengths, which corresponds to the commonly used term in seismology, seismic near-field [2], and does not depend on the source type such as seismic earthquake, blasting, or any other seismic source.

Although only about $1 \%$ of seismic events cause serious effects in mine workings [3], their analysis is very important and the basis for assessing the stability of underground workings is the analysis of the frequency characteristics of a given near-source seismic shock wave. From the point of view of the damaging effects of the mining excavation, one of the key parameters is the seismic PPV (peak particle velocity) value, which depends on the physical properties of the rock mass and the seismic source itself. The studies in $[4,5]$, for example, claim that it is the best measure of dynamic 
stress change in the rock mass and a predictor of seismic hazard. In general, the highest PPV values are recorded up to $100 \mathrm{~m}$ from the seismic foci [6], even if they have relatively small magnitudes. Butler and Van Aswegen [7] report that, in gold mines in South Africa, PPV values near the seismic source are often within the range $300-500 \mathrm{~mm} / \mathrm{s}$ in the case of compact and strong rocks, and in the case of strong seismic tremors with magnitudes larger than three, they may even reach values greater than $1.5 \mathrm{~m} / \mathrm{s}$. In coal mines at distances $200-300 \mathrm{~m}$ from the seismic foci, PPV values are usually of the order of a few millimeters per second and do not pose a threat to underground infrastructure [6]. A research conducted for several dozens of years in Poland by the Central Mining Institute in coal mines shows that, for a given rock mass and mining conditions, it is possible to determine PPV intervals that will cause rock bursts and damage to underground workings $[8,9]$ (see Figure 1). McGarr et al. [10] emphasize that changes in the stiffness of the rock medium may cause local disturbances in the propagation of the seismic wave and change significantly its amplitude during propagation. However, the particle velocity amplitudes always depend on the magnitude and distance to the seismic source.

Analyzing the impact of the near-source PPV values on underground working stability, it is essential to take into account not only the dominant frequency of the recorded seismic signal but also its duration in time. Due to the long exposure time, microcracks can appear in the rock mass, which significantly weaken its structure, especially in coal seams [6], and contribute to the reduction of its strength. The case of seismic vibrations lasting $0.6-0.7 \mathrm{~s}$ and PPV values within the range $0.8-1.8 \mathrm{~m} / \mathrm{s}$ in Carboniferous rocks in the conditions of the Upper Silesian Coal Basin, Poland, can be completely damaging [3]. Generally, low frequencies of seismic signals generated by induced mining seismic events cause higher dynamic loads on the underground support systems in the mine than blasts that generate seismic signals with significantly higher frequencies [8]. Moreover, higher frequencies of seismic vibrations with short duration time do not have the potential to damage the rocks [3]. He et al. [11] point out that the frequency and time analysis of the recorded seismic vibrations is crucial in assessing their effect on mine workings at a given distance. Additionally, the study in [11] shows that the strain rate that occurs in the rock mass is proportional to the velocity of seismic waves and their frequency.

For a given type of rock, it is possible to define the limiting values at which its destruction will occur. Silva et al. [12] recommend initially determining the static and dynamic properties of the surrounding rocks and then using the Holmberg-Persson empirical formula to determine the critical values for a given rock. The authors of $[13,14]$ suggest that, in the case of seismic events induced by blasting, it is possible to successfully select the charge mass of blasting and to predict the PPV values utilizing neural networks.

It should be noted that analyzing the impact of mining seismic tremors on the stability of underground workings, the superposition of static and dynamic stresses should be

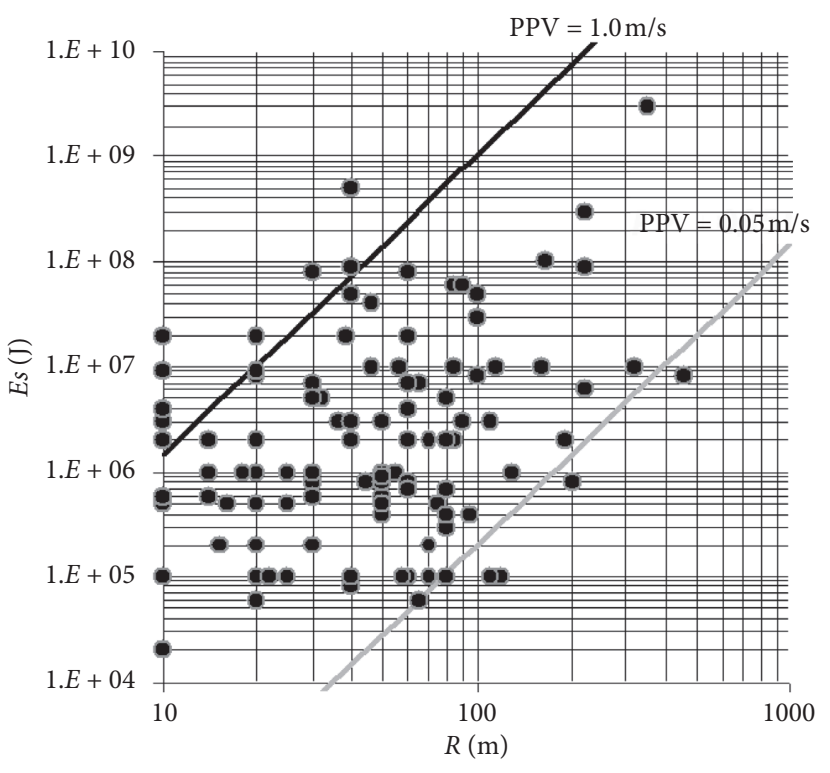

FIgURE 1: Diagram of 120 rockbursts that occurred in coal mines in Upper Silesian Coal Basin, Poland, in the years 1988-2006 as a function of distance from damaged working $R(\mathrm{~m})$ and seismic energy Es (J). Two lines of estimated constant PPV values $0.05 \mathrm{~m} / \mathrm{s}$ and $1.0 \mathrm{~m} / \mathrm{s}$ include $90 \%$ of the rockburst cases [9].

taken into account concurrently. Therefore, dynamic stress analysis should always be related to the static stress analysis, which depends on basic parameters such as rock mass density, Young's modulus, and Poisson's ratio [8]. The change of the above parameters with the change of rock mass strength will cause the variability of PPV values [5] and may indicate both an increase and a decrease of dynamic stresses. Li et al. [15] proposed a static-dynamic stress superposition approach to assess the loss of excavation stability in mines. He et al. [16], in turn, proposed the so-called Index of Static and Dynamic Stress (ISD), which is based on the highest to lowest PPV ratio recorded in a given area of the mine. This index also allows for the assessment of the hazard of rock burst occurrence in specific mining and geological conditions.

An interesting approach to analyze near-fault, pulse-like ground motions caused by tectonic earthquakes was introduced by [17] where modified Gabor wavelet was utilized to characterize near-source-ground motions. Subsequently, the study in [18] proposed wavelet analysis to extract the largest velocity pulse from a recorded ground motion. These two methods make it possible to develop quantitative criteria for classifying near-source ground motions and are very useful for seismology and engineering applications. Similar approaches have extensively been investigated by seismologists and engineers. The authors of [19-21] show clearly the importance of the seismic near-source ground motion analysis.

The main objective of the paper is to introduce continuous wavelet transform in the analysis of near-source seismic signals in underground mines. We have proposed a novel time-frequency approach to decompose recorded seismic vibrations generated by both mining seismic tremors 
and blasting during mining operations in coal mines. We have analyzed selected recordings of seismic signals of two high energy seismic events and two underground blasts showing the simultaneous importance of dominant frequencies and time duration of seismic signals. The presented approach made it possible to compare different types of seismic vibrations generated by seismic events and blasts and assessing their potential influence on the stability of underground mine workings.

\section{Materials and Methods}

Our experiment consisted of time-frequency analysis with the use of a continuous wavelet transform of recorded nearsource ground motions generated by two high energy mining seismic events and two underground blasts. The analyzed seismic signals come from two experiments carried out in Rydultowy and Bielszowice coal mines with high seismic hazard conditions in the Upper Silesian Coal Basin, Poland.

\subsection{Test Sites Description}

2.1.1. Rydyltowy Coal Mine, Upper Silesia, Poland. The test site with the plotted high energy seismic event, blasting, and the measurement point are shown in Figure 2. The test site in Rydultowy coal mine is located in the area of the coal panel no. IIIE-E1 at the depth of $1180 \mathrm{~m}$. The seismic measurements occurred from February 2020 to February 2021 and during this time, 2925 induced seismic events with energies from $10^{1}(\mathrm{~J})$ to $10^{8}(\mathrm{~J})$ were observed. Some of these events were related to the blasting works conducted in the coal panel no. IIIE-E.

In the area of the test site, a multichannel Seismological Observation System (SOS) was installed. The recordings of seismic phenomena were carried out by 11 underground seismic probes installed near coal panel no. IIIE-E1. All seismic sensors recorded seismic vibrations in the frequency range from $1 \mathrm{~Hz}$ to $500 \mathrm{~Hz}$, and our triaxial PPV seismic probe has recorded the seismic velocity amplitudes within the range $\pm 1 \mathrm{~m} / \mathrm{s}$ (see Figure 2).

2.1.2. Bielszowice Coal Mine, Upper Silesia, Poland. The test site with the plotted analyzed high energy seismic event, blasting, and the measurement point are shown in Figure 3. The test site in Bielszowice mine is located in the area of coal panel no. 314 at the depth of $1050 \mathrm{~m}$. The seismic measurements have been conducted from April 2020 to November 2020 and during this time 183 induced seismic events with energies from $10^{2}(\mathrm{~J})$ to $10^{7}(\mathrm{~J})$ were recorded. Some of them were related to the blasting works conducted in the coal panel no. 314 area.

In the area of the test site, a multichannel Seismological Observation System (SOS) with Sejsgram and Multilok seismological analysis software was installed. The recordings of seismic phenomena were carried out by 10 underground seismic probes installed near coal panel no. 314. All seismic sensors recorded seismic vibrations in the frequency range from $1 \mathrm{~Hz}$ to $500 \mathrm{~Hz}$, and our triaxial PPV seismic probe has recorded the seismic velocity amplitudes within the range $\pm 1 \mathrm{~m} / \mathrm{s}$ (see Figure 3 ).

\subsection{Estimation of Dynamic Stress State with Peak Particle} Velocity Parameter and Mine Underground Working Stability. Near-source seismic measurements conducted in our experiment in two Polish underground mines have been possible with the use of specially designed seismic probes that enable the recording of high peak particle velocity values (PPV) within the range of $1-1000 \mathrm{~mm} / \mathrm{s}$. PPV is an essential parameter due to the fact that it can be directly related to dynamic stresses in the rock mass [22]. Hence, PPV is widely applied as an indicator in assessing the influence of vibrations on underground infrastructure and is crucial in assessing rock burst hazard in underground workings.

The measured or estimated PPV values are proportional to the maximum normal $\left(\sigma_{P}\right)$ dynamic stresses associated with the seismic longitudinal P-waves that are generated by seismic sources [22]:

$$
\sigma_{P}=\frac{(1-v) E}{(1+v)(1-2 v)} \frac{\mathrm{PPV}_{p}}{c_{p}},
$$

and maximum shear $\left(\tau_{S}\right)$ dynamic stresses associated with the seismic shear S-waves [22]:

$$
\tau_{P}=\frac{G v_{s}}{c_{s}}=\rho \cdot \mathrm{PPV}_{P} \cdot c_{s},
$$

where $\mathrm{PPV}_{p}$ is the peak particle velocity of the seismic $\mathrm{P}$-wave $(\mathrm{m} / \mathrm{s}), \rho$ is the density of the medium $\left(\mathrm{kg} / \mathrm{m}^{3}\right), E$ is Young's modulus $(\mathrm{Pa}), G$ is the shear modulus $(\mathrm{Pa}), v$ is Poisson's ratio, $c_{P}$ is the seismic P-wave velocity $(\mathrm{m} / \mathrm{s})$, and $c_{S}$ is the seismic S-wave velocity $(\mathrm{m} / \mathrm{s})$.

In formulas (1) and (2), the homogeneity of the rock medium is assumed.

The multiannual monitoring of rock bursts cases in underground coal mines in the Upper Silesian Coal Basin, Poland, indicates that high energy mining seismic events can cause at least partial damage to underground mine excavations if they are located no farther than 300 meters away. Measurements and empirical research conducted in the Upper Silesian Coal Basin, Poland, have enabled us to analyze 120 rock bursts cases that occurred in USCB coal mines between 1988 and 2006 and relate the observed damaging effects with the peak particle velocity parameter PPV. Figure 1 shows that the damage to mine excavations occurred in $90 \%$ of the total cases for the estimated PPV value between $0.05 \mathrm{~m} / \mathrm{s}$ and $1.0 \mathrm{~m} /$ $s$ [9]. We would like additionally to emphasize that we did not consider any other factors having significant influence on damage to mine excavations such as preexisting stress field near the underground workings or rock damage criteria. If one wants to analyze preexisting stress field, for example, then it cannot be measured directly and one has to rely on some modelling software such as FLAC 3D which causes the accuracy of such method to be very questionable. Therefore, we decided to utilize one parameter only, i.e., PPV parameter, to assess its influence on underground working stability showing 


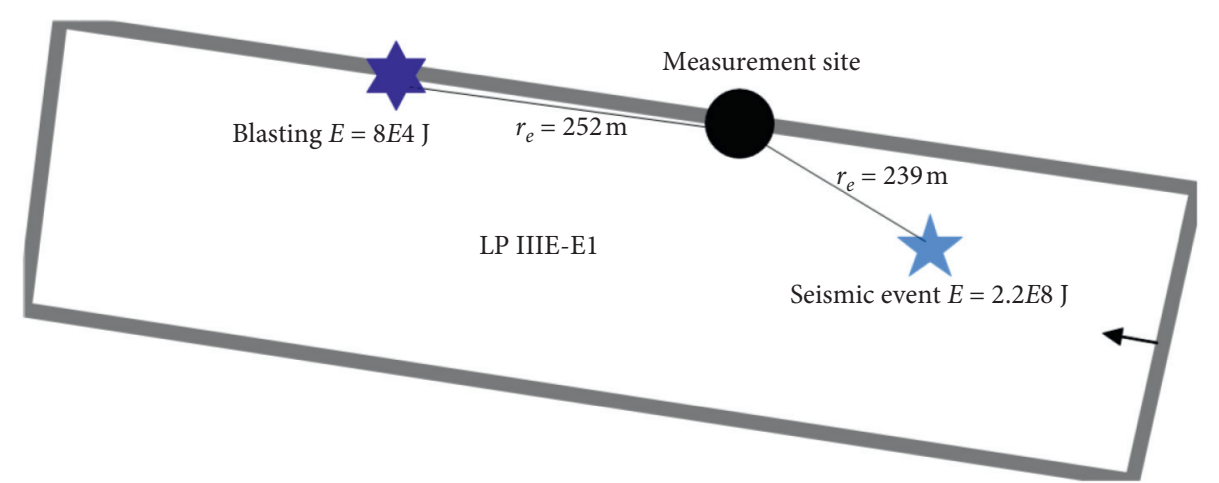

FIgure 2: Upper Silesian Coal Basin, Poland. Rydultowy coal mine, area of coal panel no. IIIE-E1. Plan view of experimental site.

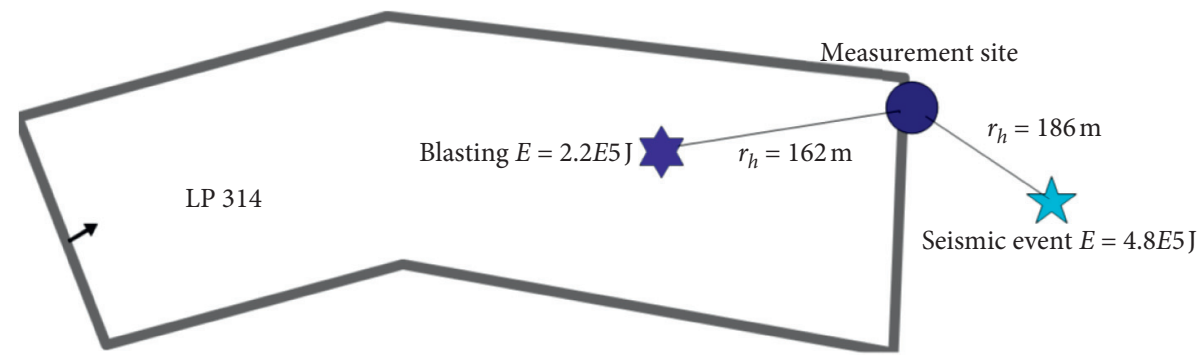

Figure 3: Upper Silesian Coal Basin, Poland. Bielszowice coal mine, area of coal panel no. 314. Plan view of experimental site.

additionally that time-frequency characteristic of seismic signals can provide deeper insight into the relation between PPV parameter and underground working stability itself. This relation is not unique, because many other factors play an important role and these factors cannot be determined with sufficient accuracy. Therefore, our analysis between PPV and time-frequency characteristic of the seismic signal has statistical or probabilistic meaning and is not deterministic and is expressed empirically by data shown in Figure 1.

2.3. Continuous Wavelet Transform. Time-frequency analysis is a technique used to determine the frequency content of local sections of a time-varying signal as it changes over time. One of the widespread techniques of time-frequency analysis of time-dependent signals is Short Time Fourier Transform (STFT). However, the main disadvantage of STFT technique is the resolution problem related to the time windowing function. A wide time window provides good frequency resolution but poor time resolution, and conversely, narrower time window provides good time resolution but poor frequency resolution. This is the main reason why we have used in our analysis of seismic records the continuous wavelet transform, which can yield both good time and frequency resolutions of time-varying signals.

Continuous wavelet transform of a time function $x(t)$ has two parameters and has the following form:

$$
X_{\psi}(a, b)=\frac{1}{|a|^{1 / 2}} \int_{-\infty}^{\infty} x(t) \bar{\psi}\left(\frac{t-b}{a}\right) \mathrm{d} t
$$

where $a$ and $b$ are wavelet transformation parameters that can be related to the frequency distribution of the time signal $x(t)$ at a given moment of time $t . \psi(t)$ is a complex and continuous function both in the time domain and in the frequency domain and is called the mother wavelet. The line sign above $\psi(t)$ represents a complex conjugate. $X_{\psi}(a, b)$ is a two-parameter complex wavelet transform of a function $x(t)$ with kernel $\psi(t)$.

There are many types of analytic mother wavelets utilized in (1) and we have decided to use Morse wavelet. Morse wavelet is very useful in analyzing modulated signals with time-varying amplitude and frequency and our strong motion seismic recordings definitely belong to this group of signals [23].

There are many applications of the wavelet transform such as image compression where significant improvement in image quality is achieved with higher compression ratios compared to conventional techniques. The concept of wavelet transform is broadly applied to denoise or compress time-varying signals. In seismology, continuous wavelet transform (CWT) has extensively been used to investigate the characteristics of pulse-like motions [18], for example, utilizing the concept of signal denoising by wavelet analysis to extract the short-time velocity pulses from earthquake recordings and forming a special classification procedure for recorded near-source seismic ground motions.

The wavelet transform allows decomposition of the timevarying signal $x(t)$ into instantaneous frequencies in a given time and we have used this approach. Continuous wavelet transforms are also used in the following areas: edge detection, solving partial differential equations, transient detection, filter design, electrocardiographic (ECG) analysis, texture analysis, business information analysis, and gait analysis. The wavelet transformation was also used to interpret the time histories of landslides. 


\section{Results and Discussion}

During our research experiment, we have found that nearsource seismic vibrations generated by two high energy seismic tremors and two blasts in Bielszowice and Rydultowy mines in Poland are highly nonstationary stochastic processes (see Figures 4-15. This means that the analysis of these vibrations using, for example, standard methods of Fourier analysis can be insufficient to select dominant frequencies due to the fact that stochastic processes can have varying bandwidth of dominant frequencies in separate time intervals. This, in turn, has led us to the conclusion that high resolution time-frequency analysis that utilizes the continuous wavelet transform method is required. Time-frequency analysis makes it possible to distinguish the characteristics of seismic signals in individual time intervals of the measured near-source seismic signals. We have found that the recorded near-source seismic ground motions are nonstationary with seismic wave packets of variable dominant frequencies in the range from a few to several tens of hertz.

We have utilized in our analysis an important observation that seismic PPV values with high frequency bandwidth are less dangerous than PPV values with significantly lower frequency bandwidth. For example, in [24], it was observed that, after blasting, PPV values can be very high, but they also have very high frequency bandwidth with no damaging effect on underground mine workings, even when the PPV values are greater than $1 \mathrm{~m} / \mathrm{s}$. The frequency characteristics of the seismic vibrations generated by numerous low energy seismic events appear to be very similar to blasting and therefore are not dangerous for excavation stability.

Figures 4-15 show the recorded near-source velocity seismograms, its amplitude Fourier spectrum, and the continuous wavelet transform (CWT) recorded in three perpendicular directions, $X, Y$, and $Z$, for each recording. The CWT allow for the analysis of frequency components for individual parts of the recorded seismic time signal of the particle vibration velocity, obtaining information that is not available for the ordinary amplitude Fourier spectrum. Generally, it can be noted that the dominant frequency range is greater than $20 \mathrm{~Hz}$ for all recorded seismic signals except the triaxial particle velocity amplitudes generated from seismic event from Bielszowice mine with seismic energy $8 * 10^{4}(\mathrm{~J})$.

Figures 4-6 present the recorded velocity seismograms of triaxial geophone probe at the distance of $240 \mathrm{~m}$ from a seismic event with energy $2 * 10^{8}(\mathrm{~J})$ in Rydultowy coal mine. It was the strongest seismic tremor recorded in the analyzed period for both mines. The PPV values for $X, Y$, and $Z$ components are $25 \mathrm{~mm} / \mathrm{s}, 46 \mathrm{~mm} / \mathrm{s}$, and $81 \mathrm{~mm} / \mathrm{s}$, respectively, and the PPV value for the full $X Y Z$ vector is $83 \mathrm{~mm} / \mathrm{s}$. The calculated amplitude Fourier spectra for $X, Y$, and $Z$ components have dominant frequencies between $1 \mathrm{~Hz}$ and $10 \mathrm{~Hz}$, whereas there are two additional visible frequency bands in the ranges $20 \mathrm{~Hz}-30 \mathrm{~Hz}$ and $40 \mathrm{~Hz}-50 \mathrm{~Hz}$. Much more detailed time-frequency information can be gained from the continuous wavelet transform (CWT), where several dominant frequency groups are visible in separate time intervals. From the assessment of underground working stability point of view, the most important are the groups of lower frequencies in the ranges $1-20 \mathrm{~Hz}$ and $20-40 \mathrm{~Hz}$ that are clearly seen on all three $X, Y$, and $Z$ velocity CWT spectrograms. The $1-20 \mathrm{~Hz}$ group of frequencies on the CWT spectrogram lasts generally longer than $20-40 \mathrm{~Hz}$ group of frequencies that has a rather adverse effect on underground working stability. Additionally, we show in Figure 16 the 3D particle velocity ground motion that represents the 3D movement of the particles in the rock mass nearby the installed seismic probe. One can easily observe that this $3 \mathrm{D}$ motion has one dominant direction that runs approximately along the $Z$ axis. This is the characteristic particle motion movement for the fault slip source mechanism.

Figures $10-12$ present the recorded velocity seismograms of a triaxial geophone probe at the distance of $186 \mathrm{~m}$ from a seismic event with energy $5 * 10^{5}(\mathrm{~J})$ in the Bielszowice coal mine. The PPV values for $X, Y$, and $Z$ components are $7.8 \mathrm{~mm} / \mathrm{s}, 8.2 \mathrm{~mm} / \mathrm{s}$, and $2.8 \mathrm{~mm} / \mathrm{s}$, respectively, and the PPV value for the full $X Y Z$ vector is $10 \mathrm{~mm} / \mathrm{s}$. The calculated amplitude Fourier spectra for $X, Y$, and $Z$ components have clearly visible dominant frequencies between $20 \mathrm{~Hz}$ and $30 \mathrm{~Hz}$, whereas there are two additional visible frequency bands in the ranges $50 \mathrm{~Hz}-60 \mathrm{~Hz}$ and $70 \mathrm{~Hz}-80 \mathrm{~Hz}$, but only for $Z$ component. More detailed time-frequency information can be gained from the continuous wavelet transform (CWT), where several dominant frequency groups are only visible for $Z$ component in separate time intervals. From the assessment of underground working stability point of view, the most important is the group of lower frequencies in the range $20-30 \mathrm{~Hz}$ and clearly seen on all three $X, Y$, and $Z$ velocity CWT spectrograms. The $20-30 \mathrm{~Hz}$ group of frequencies on the CWT spectrograms lasts generally about 300 milliseconds and has an adverse influence on underground working stability. It is also interesting to point out that, on CWT spectrograms $20-30 \mathrm{~Hz}$, visible frequency band is probably related to resonant frequency of some structure in the rock mass rather than directly related to the seismic source. We also show in Figure 17 the 3D particle velocity ground motion that represents the $3 \mathrm{D}$ movement of the particles in the rock mass nearby the installed seismic probe. Similar to the recorded vibration from the seismic event in Rydultowy coal mine, one can easily observe that this $3 \mathrm{D}$ motion has one dominant direction that runs in the $X Y$ plane and is characteristic to particle motion movement for fault slip source mechanism.

Figures 7-9 present the recorded velocity seismograms of the triaxial geophone probe at the distance of $252 \mathrm{~m}$ from blasting on 2020-07-25 with charge weight $72 \mathrm{~kg}$ and estimated seismic energy $8 * 10^{4}(\mathrm{~J})$ in Rydultowy coal mine. The PPV values for $X, Y$, and $Z$ components are $1.3 \mathrm{~mm} / \mathrm{s}, 3.1 \mathrm{~mm} / \mathrm{s}$, and $3.4 \mathrm{~mm} / \mathrm{s}$, respectively, and the PPV value for the full $X Y Z$ vector is $5.4 \mathrm{~mm} / \mathrm{s}$. The calculated amplitude Fourier spectra for $X$ and $Z$ components have clearly visible dominant frequencies between $20 \mathrm{~Hz}$ and $50 \mathrm{~Hz}$, whereas there is an additional visible frequency band in the range $50 \mathrm{~Hz}-90 \mathrm{~Hz}$ for all three components. More detailed time-frequency information is obtained 


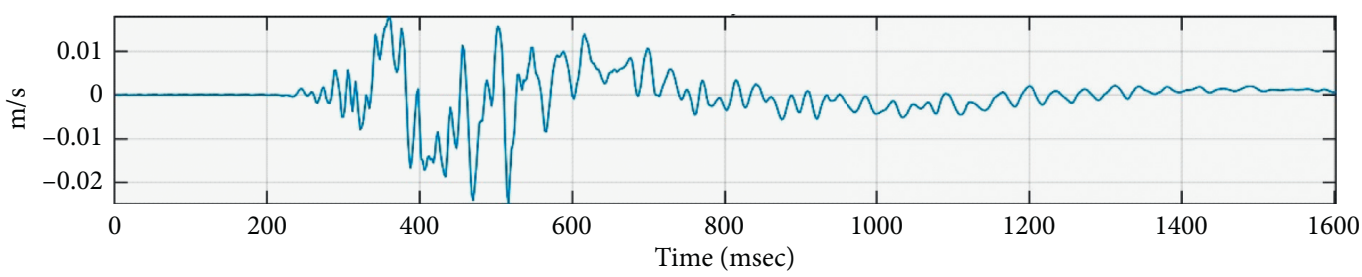

(a)

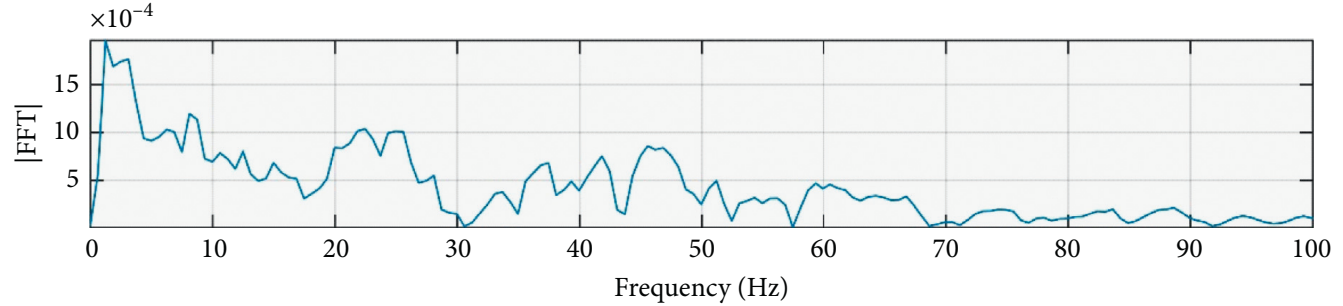

(b)

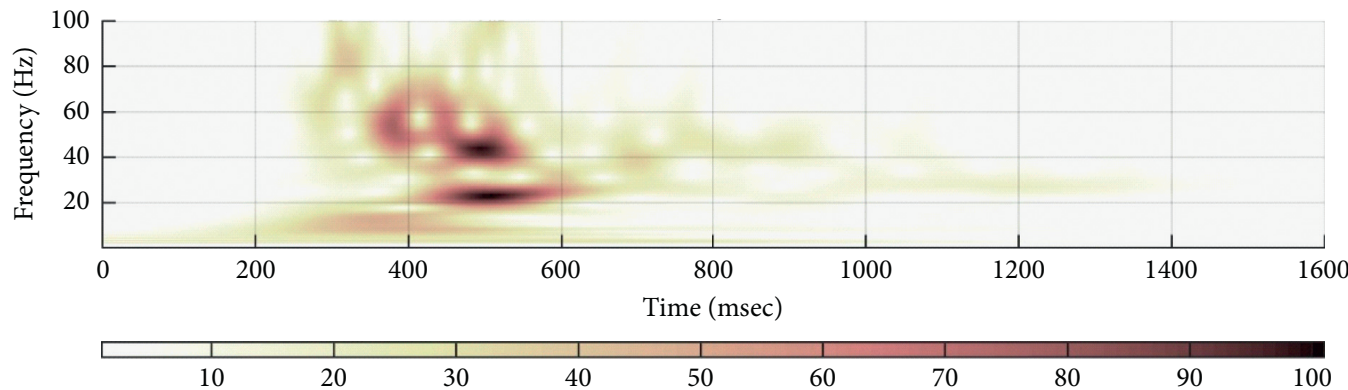

(c)

FIGURE 4: $X$ component of recorded near-source seismic ground motion in Rydultowy coal mine from seismic event that occurred on 202007-21 with seismic energy $2 * 10^{8}(\mathrm{~J})$. (a) Velocity seismogram $(\mathrm{m} / \mathrm{s})$; (b) amplitude Fourier spectrum; (c) continuous wavelet transform.

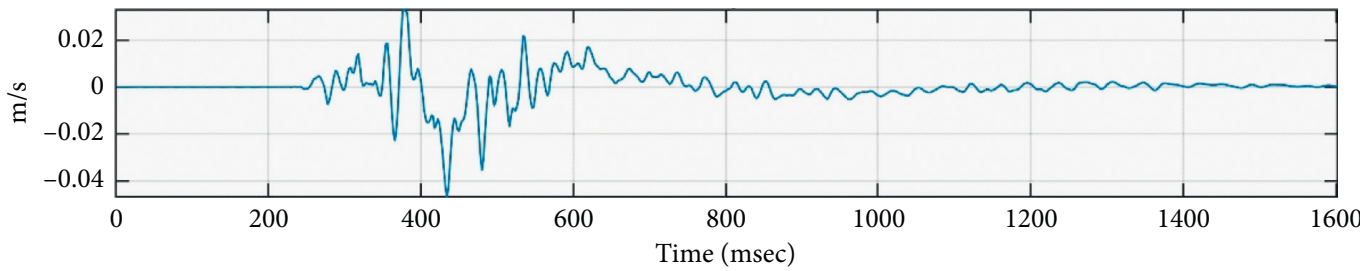

(a)

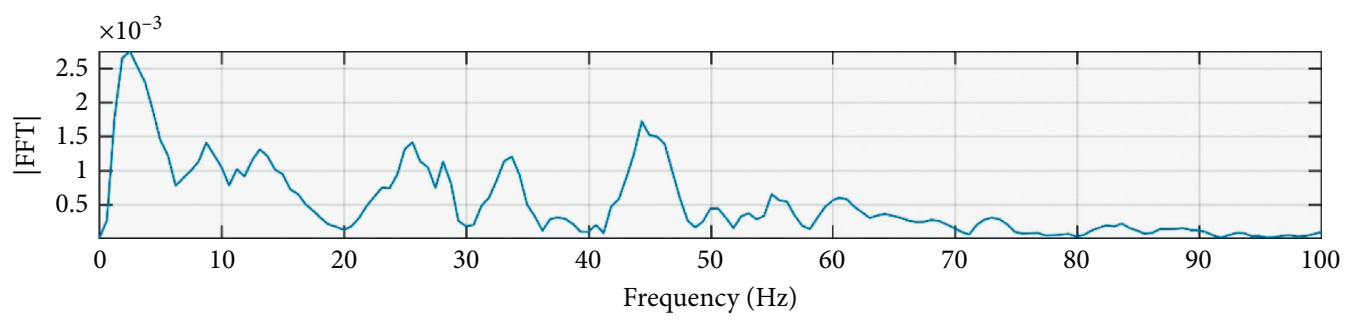

(b)

FIgUre 5: Continued. 


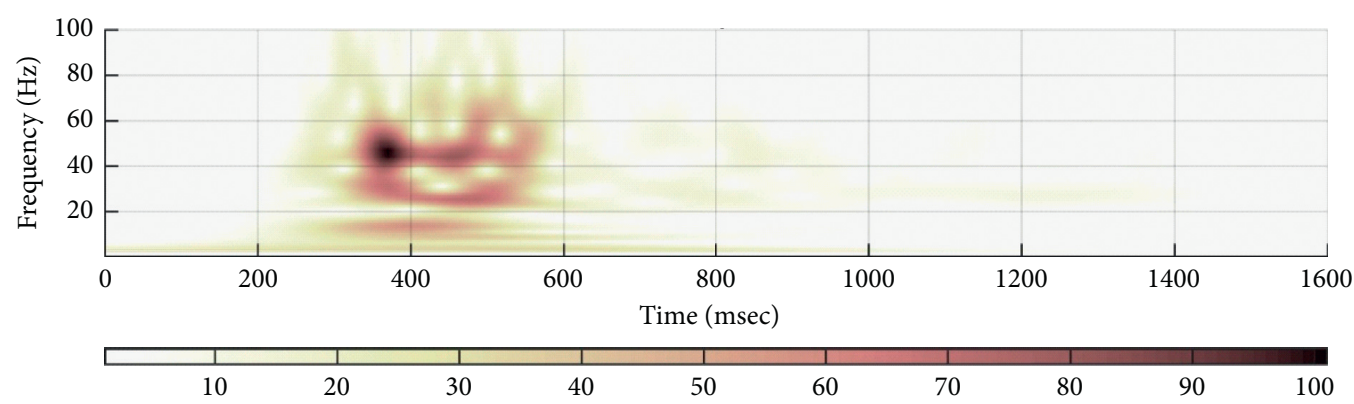

(c)

FIGURE 5: $Y$ component of recorded near-source seismic ground motion in Rydultowy coal mine from seismic event that occurred on 202007-21 with seismic energy $2 * 10^{8}(\mathrm{~J})$. (a) Velocity seismogram $(\mathrm{m} / \mathrm{s})$; (b) amplitude Fourier spectrum; (c) continuous wavelet transform.

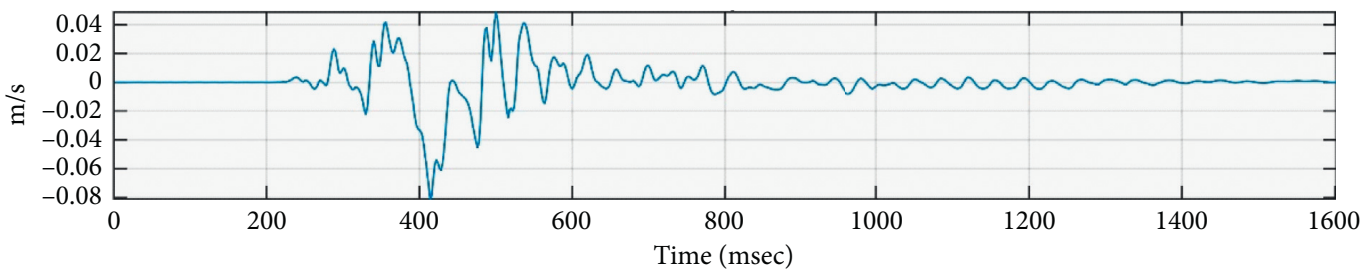

(a)

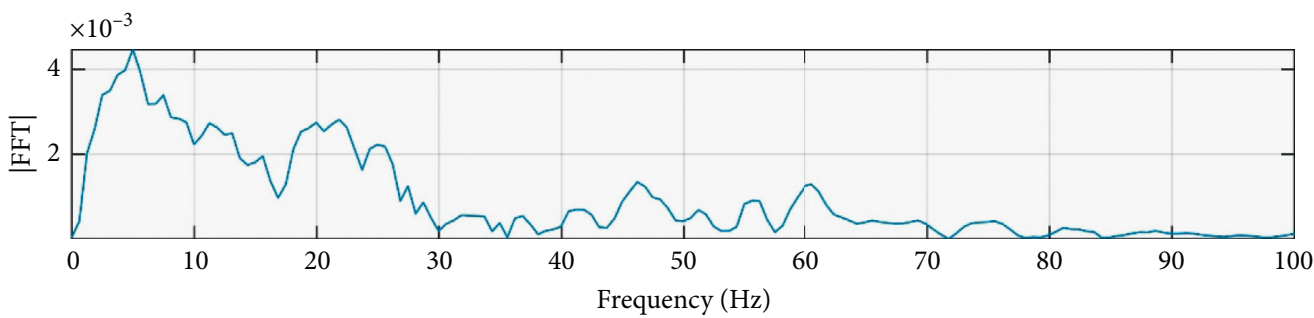

(b)

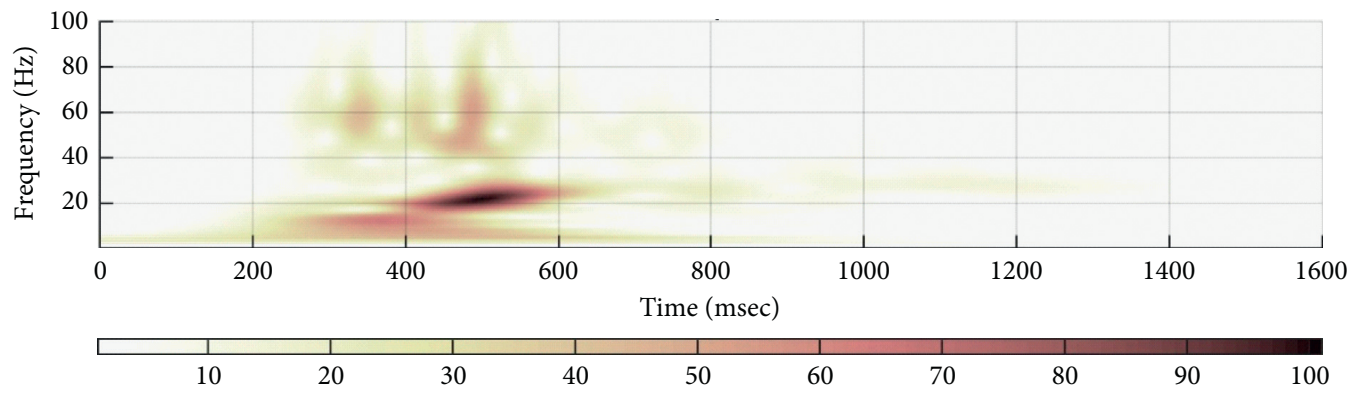

(c)

FIGURE 6: $Z$ component of recorded near-source seismic ground motion in Rydultowy coal mine from seismic event that occurred on 202007-21 with seismic energy $2 * 10^{8}(\mathrm{~J})$. (a) Velocity seismogram (m/s); (b) amplitude Fourier spectrum; (c) continuous wavelet transform.

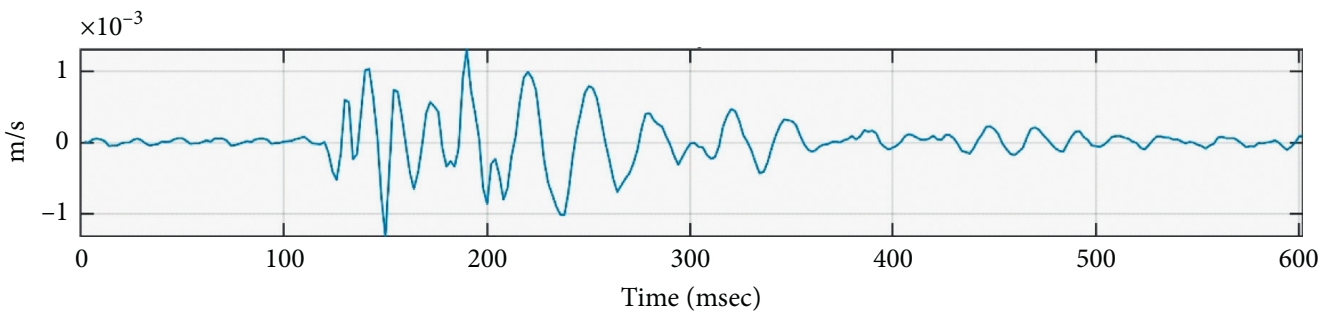

(a)

Figure 7: Continued. 


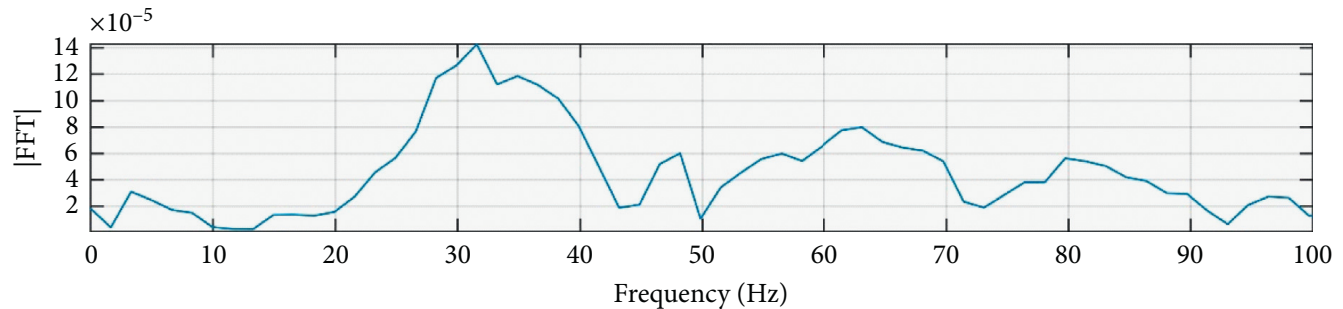

(b)

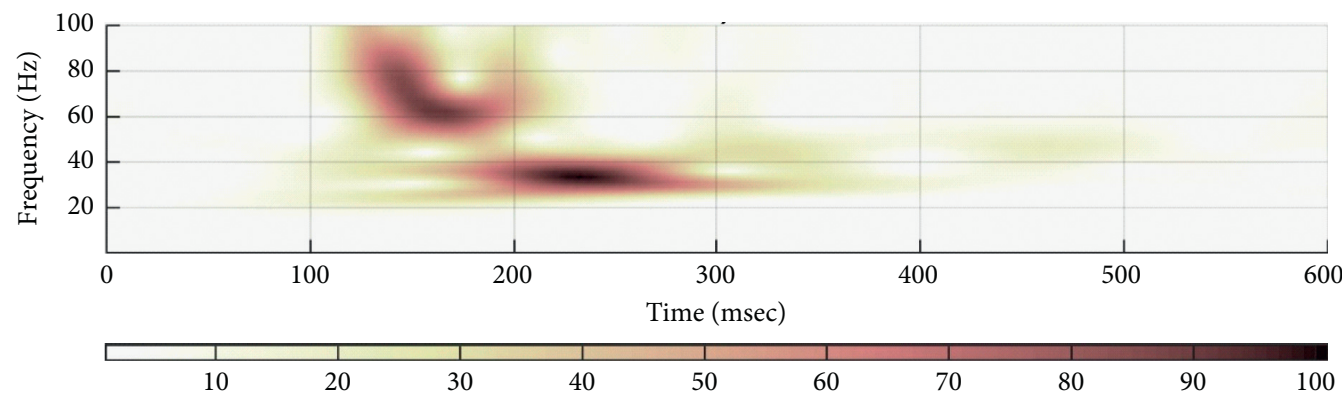

(c)

Figure 7: $X$ component of recorded near-source seismic ground motion in Rydultowy coal mine from blasting on 2020-07-25 with charge weight $72 \mathrm{~kg}$ and estimated seismic energy $8 * 10^{4}(\mathrm{~J})$. (a) Velocity seismogram $(\mathrm{m} / \mathrm{s}$ ); (b) amplitude Fourier spectrum; (c) continuous wavelet transform.

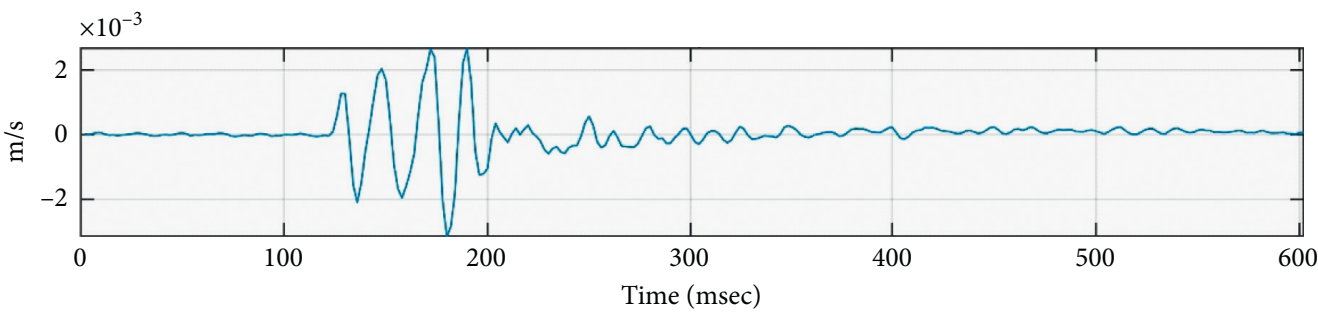

(a)

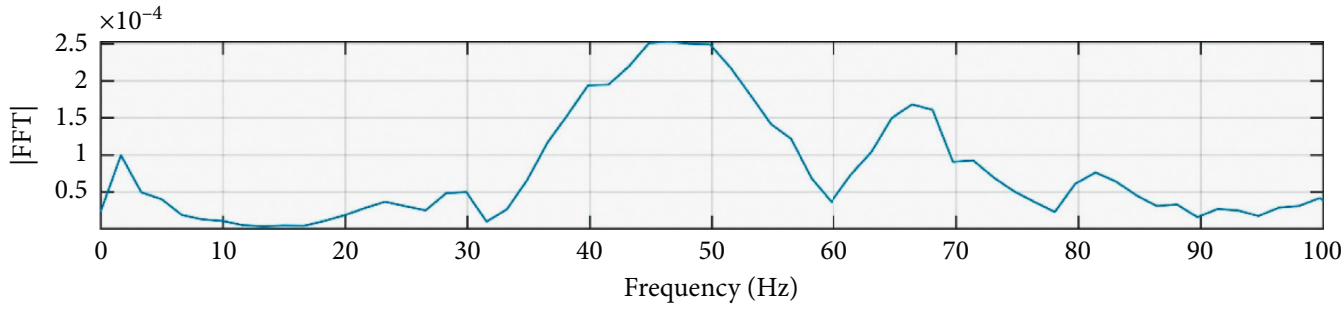

(b)

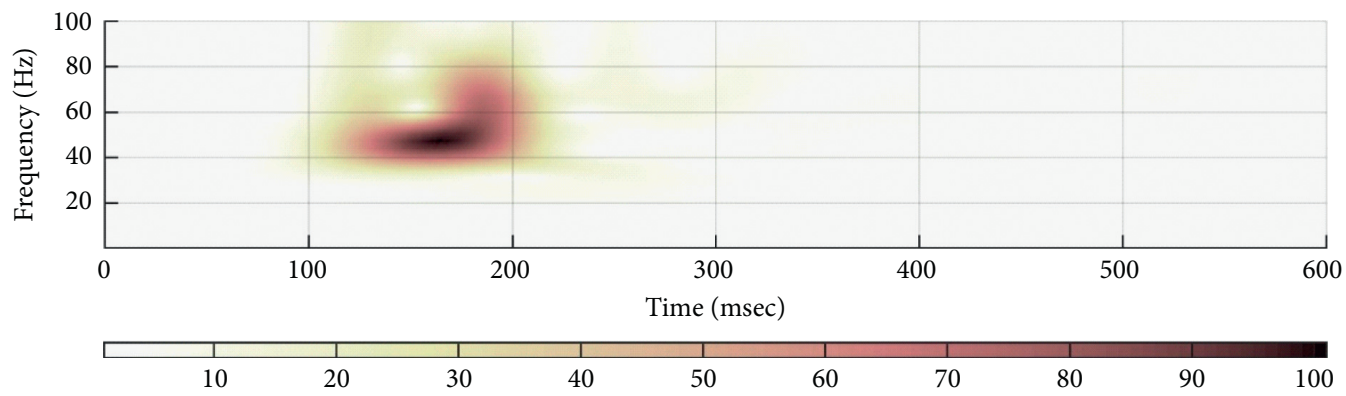

(c)

FIGURE 8: $Y$ component of recorded near-source seismic ground motion in Rydultowy coal mine from blasting on 2020-07-25 with charge weight $72 \mathrm{~kg}$ and estimated seismic energy $8 * 10^{4}(\mathrm{~J})$. (a) Velocity seismogram (m/s); (b) amplitude Fourier spectrum; (c) continuous wavelet transform. 


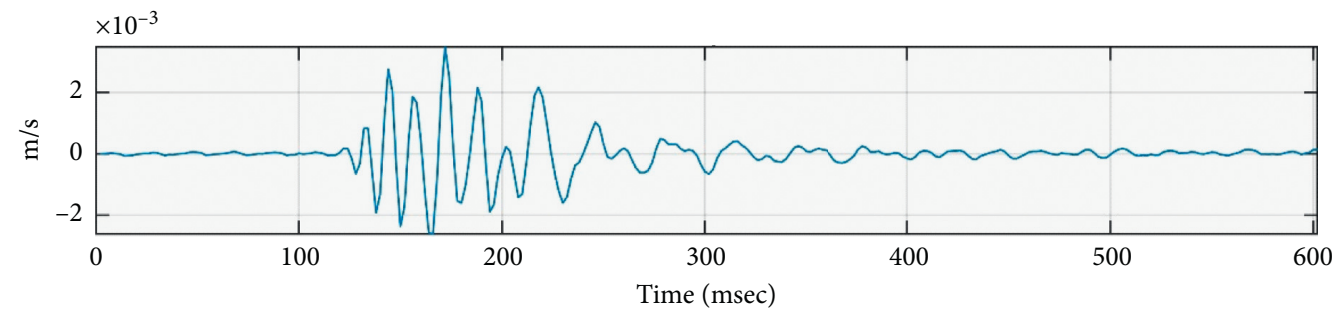

(a)

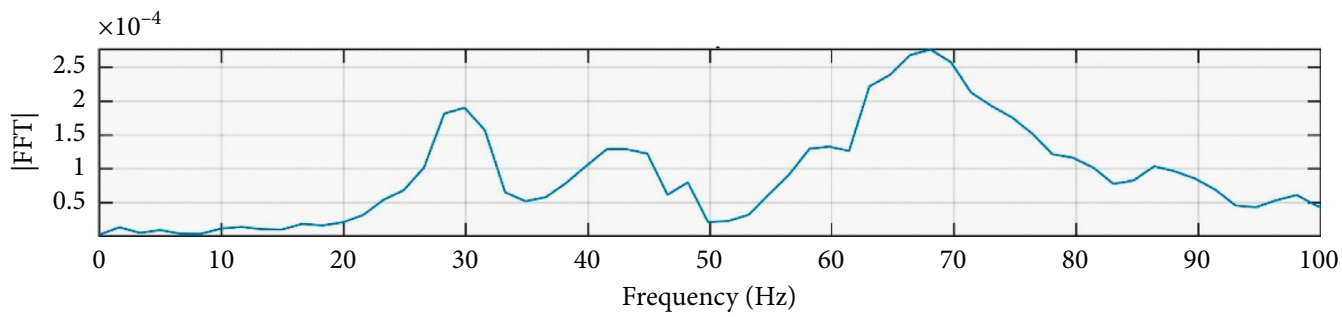

(b)

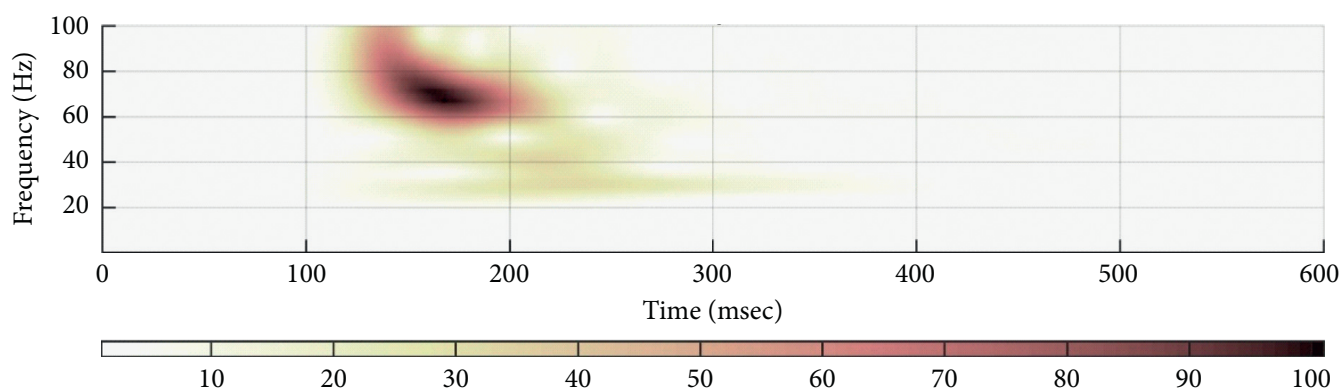

(c)

Figure 9: $Z$ component of recorded near-source seismic ground motion in Rydultowy coal mine from blasting on 2020-07-25 with charge weight $72 \mathrm{~kg}$ and estimated seismic energy $8 * 10^{4}(\mathrm{~J})$. (a) Velocity seismogram $(\mathrm{m} / \mathrm{s}$ ); (b) amplitude Fourier spectrum; (c) continuous wavelet transform.

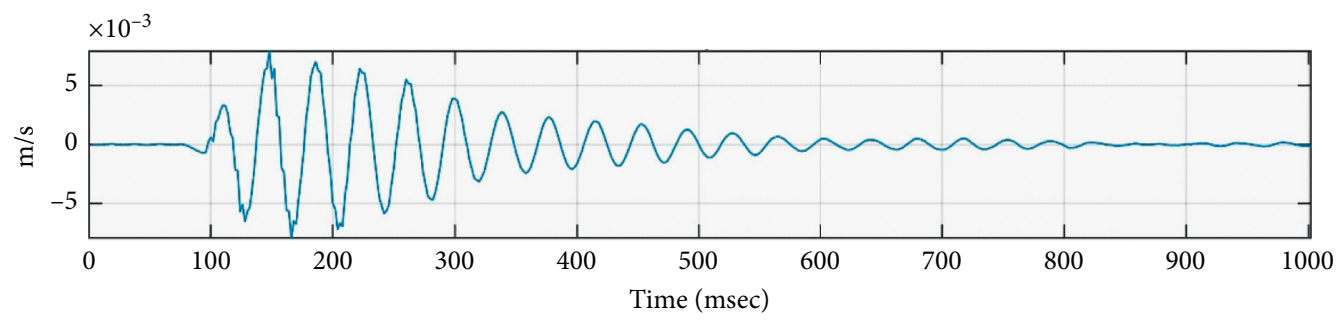

(a)

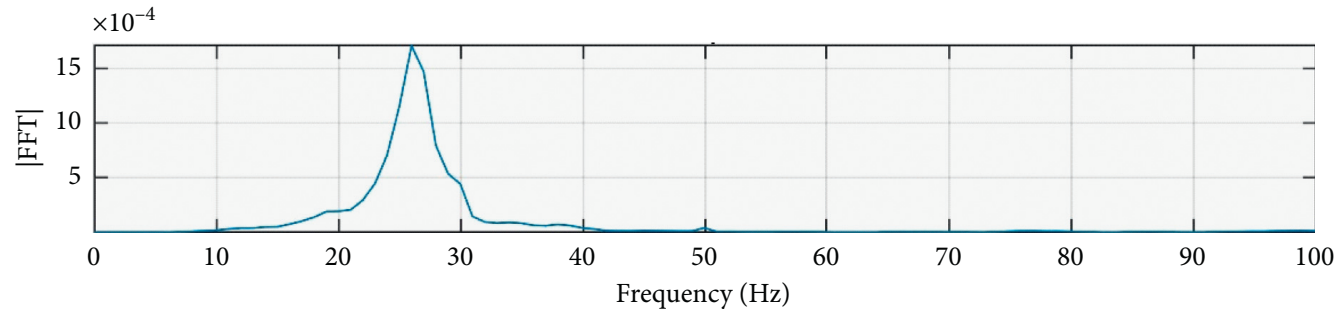

(b)

Figure 10: Continued. 


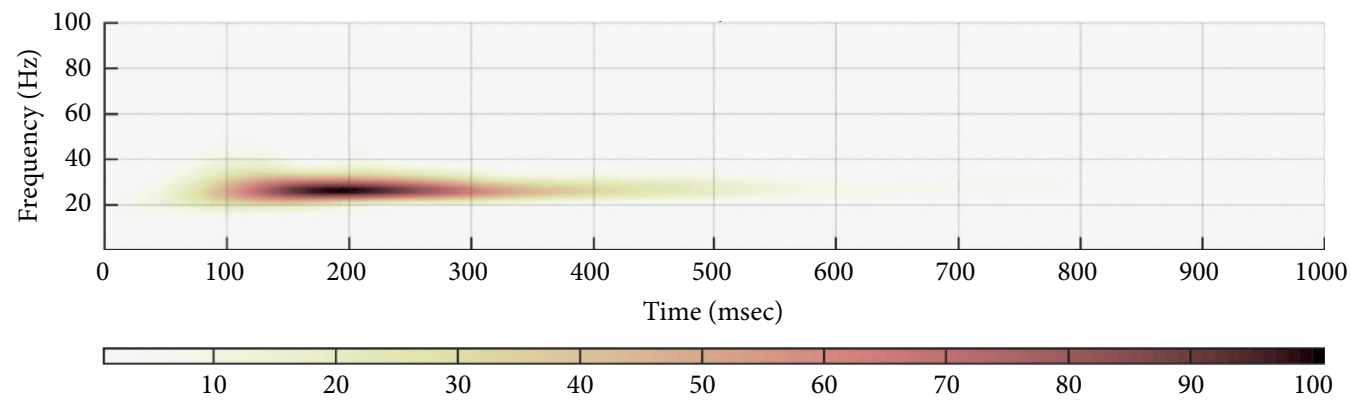

(c)

FIGURE 10: $X$ component of recorded near-source seismic ground motion in Bielszowice coal mine from seismic event that occurred on 2020-10-23 with seismic energy $5 * 10^{5}(\mathrm{~J})$. (a) Velocity seismogram $(\mathrm{m} / \mathrm{s})$; (b) amplitude Fourier spectrum; (c) continuous wavelet transform.

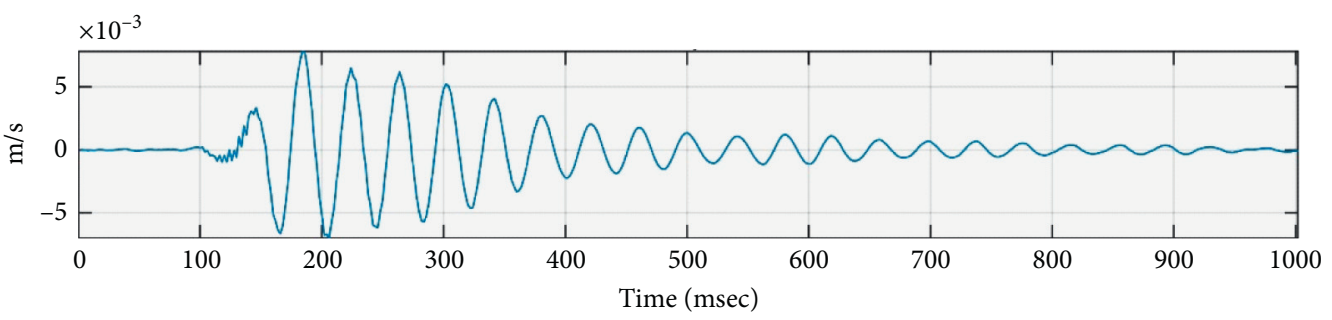

(a)

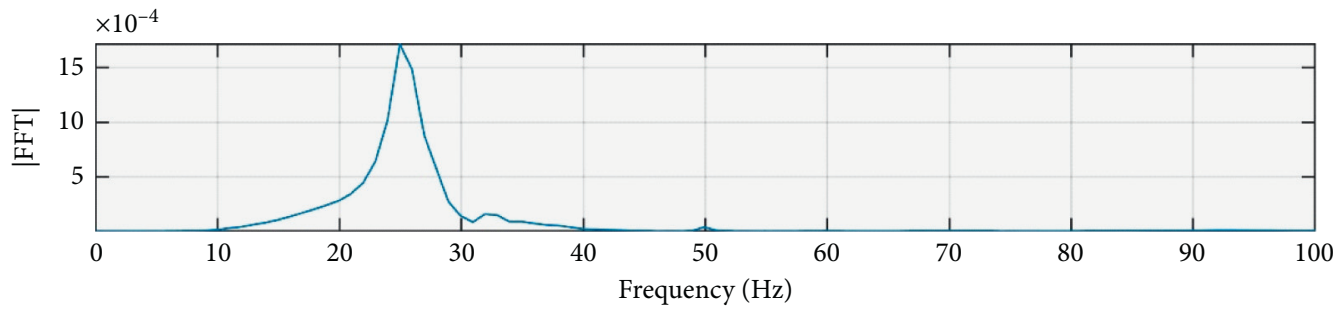

(b)

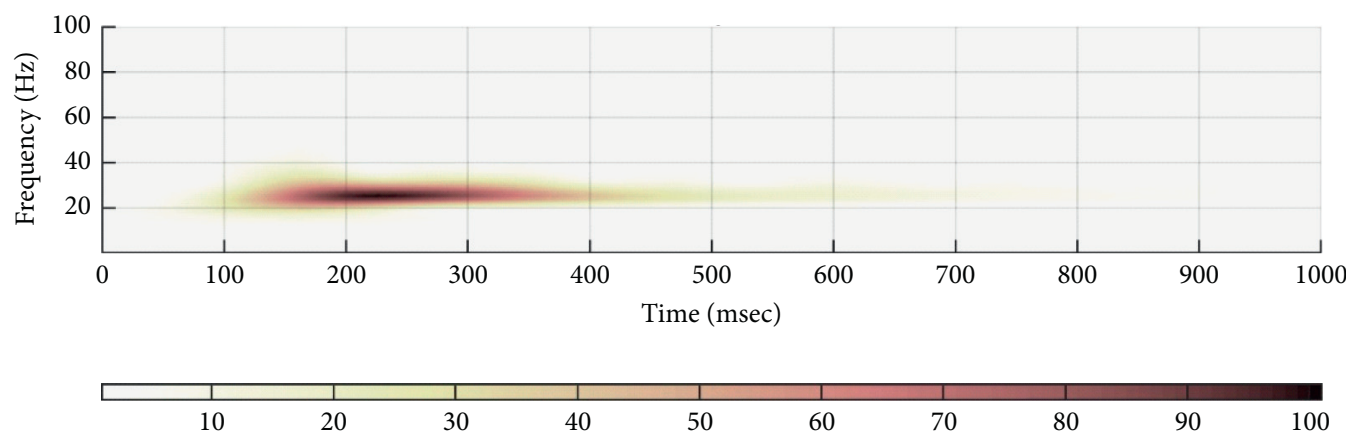

(c)

FIGURE 11: $Y$ component of recorded near-source seismic ground motion in Bielszowice coal mine from seismic event that occurred on 2020-10-23 with seismic energy $5 * 10^{5}$ (J). (a) Velocity seismogram (m/s); (b) amplitude Fourier spectrum; (c) continuous wavelet transform.

from the continuous wavelet transform, where the two dominant frequency groups are only visible for all components in separate time intervals. Comparing the calculated $X, Y$, and $Z$ CWT spectrograms with CWT spectrograms obtained for two analyzed seismic events, one can easily notice that the dominant frequency bands have been shifted towards higher frequencies. From the assessment of underground working stability point of view, this is advantageous effect. The lower $20-30 \mathrm{~Hz}$ group of frequencies on the CWT spectrograms is visible on $X$ component only and lasts generally about 200 milliseconds, what constitutes half of the duration of the recorded 


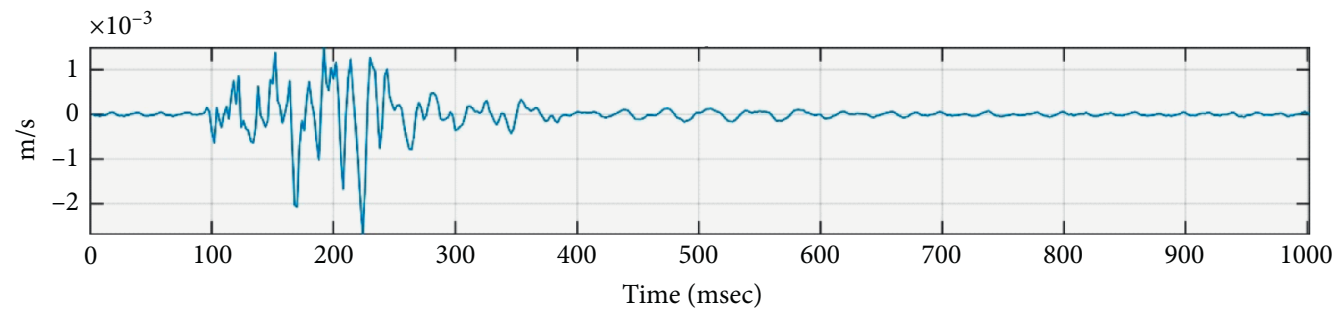

(a)

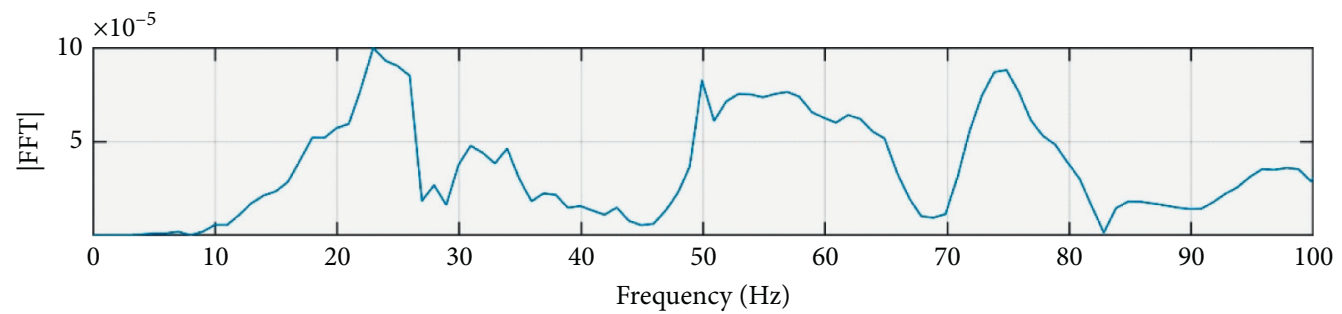

(b)
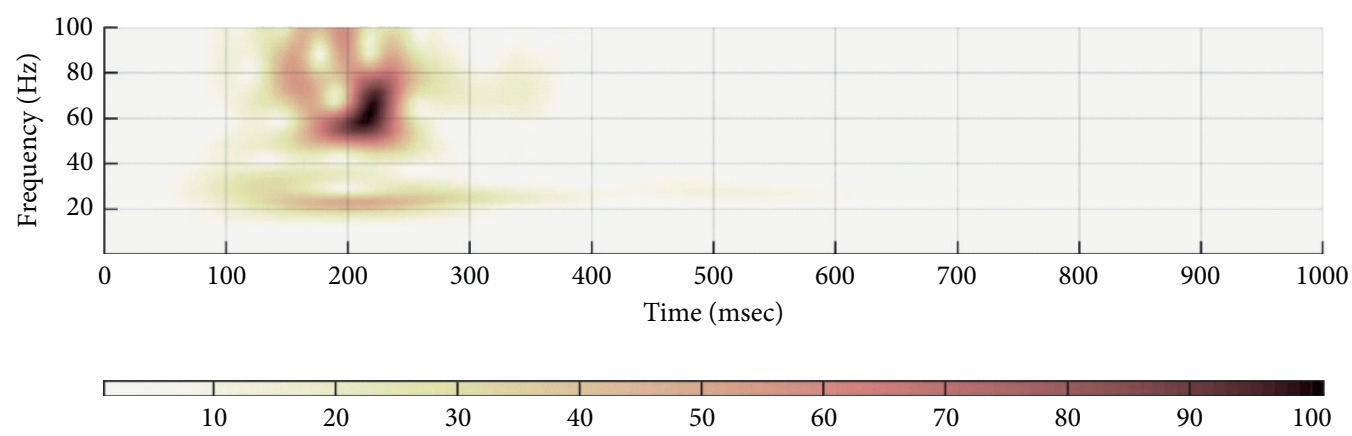

(c)

FIGURE 12: $Z$ component of recorded near-source seismic ground motion in Bielszowice coal mine from seismic event that occurred on 2020-10-23 with seismic energy $5 * 10^{5}(\mathrm{~J})$. (a) Velocity seismogram (m/s); (b) amplitude Fourier spectrum; (c) continuous wavelet transform.

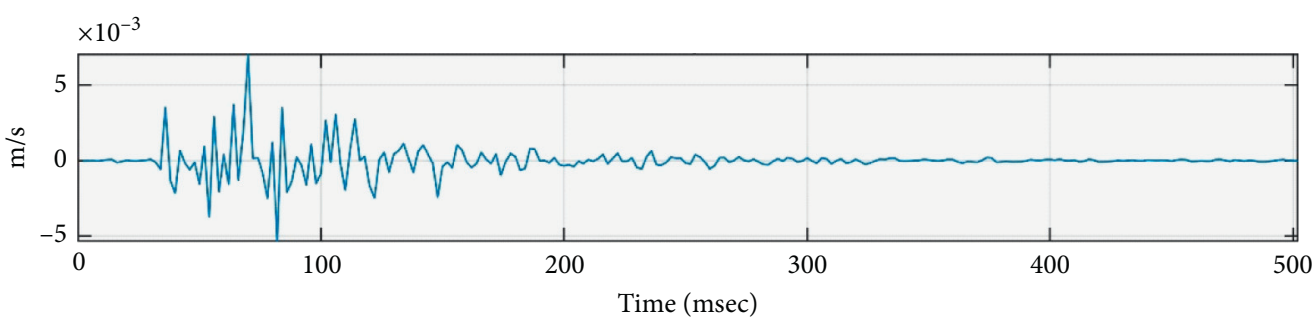

(a)

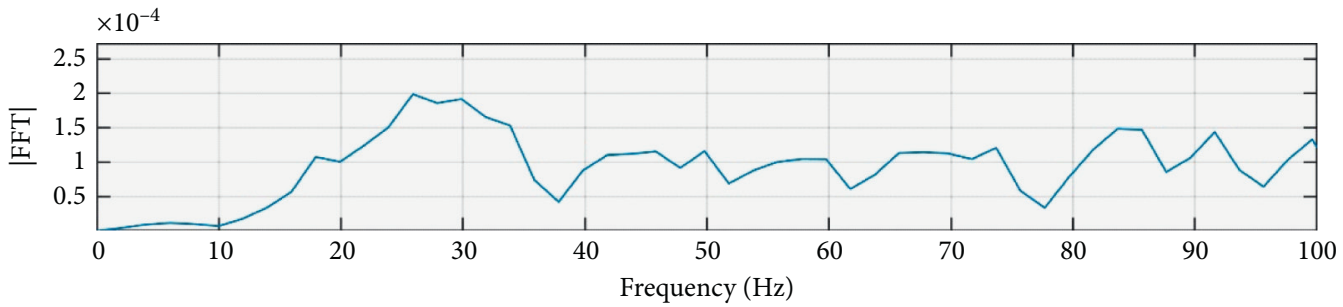

(b)

Figure 13: Continued. 


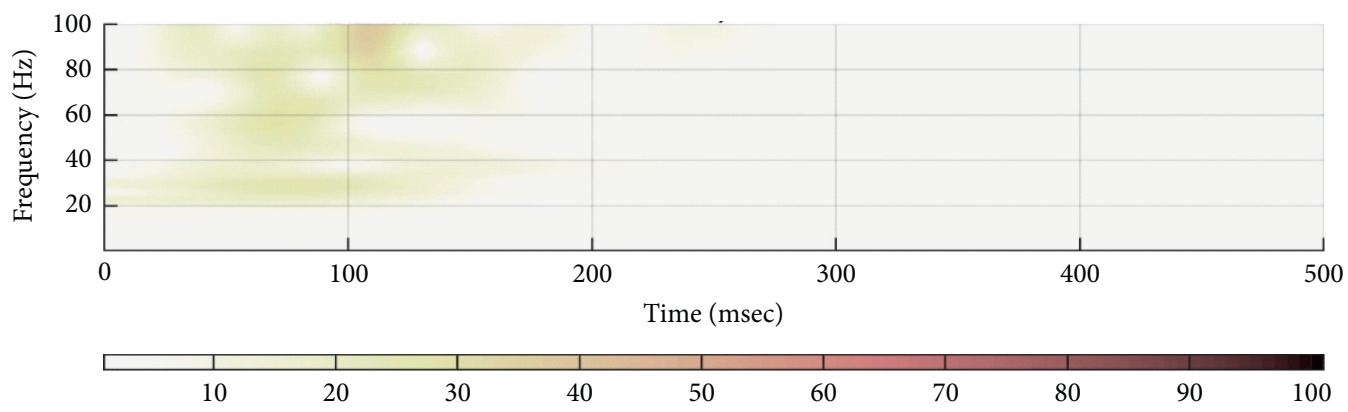

(c)

Figure 13: $X$ component of recorded near-source seismic ground motion in Bielszowice coal mine from blasting on 2020-08-16 with charge weight $192 \mathrm{~kg}$ and estimated seismic energy $2 * 10^{5}(\mathrm{~J})$. (a) Velocity seismogram (m/s); (b) amplitude Fourier spectrum; (c) continuous wavelet transform.

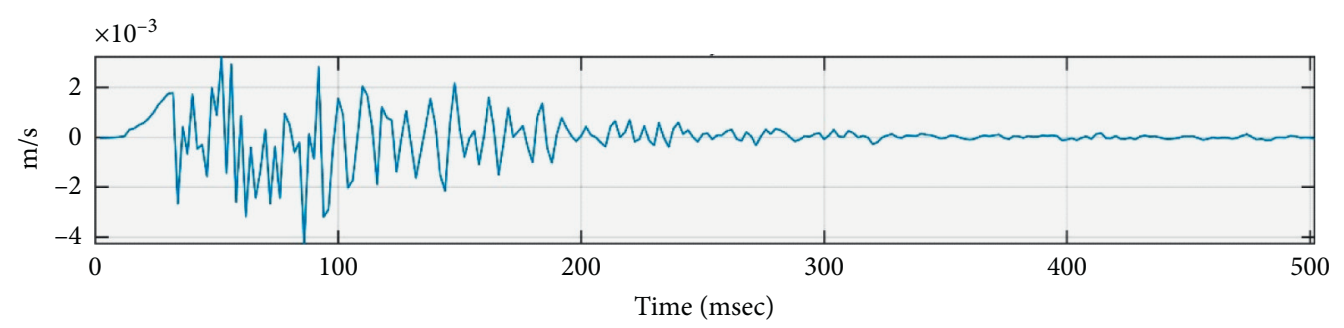

(a)

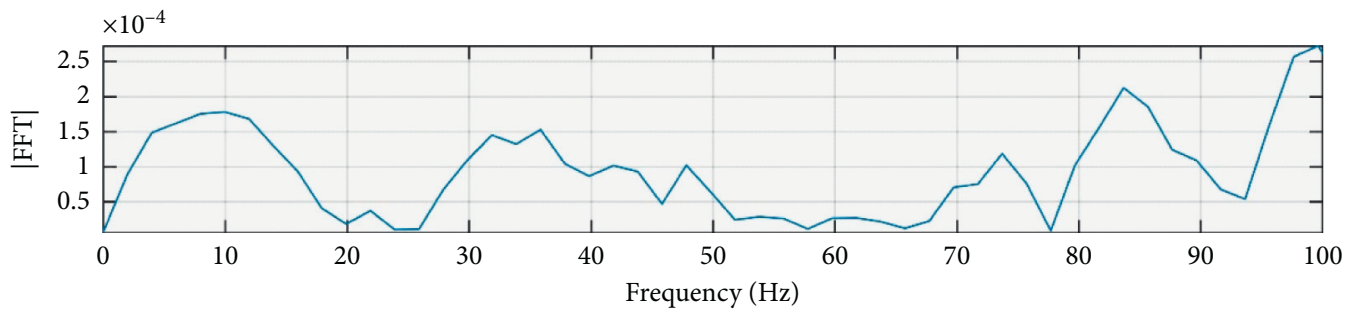

(b)

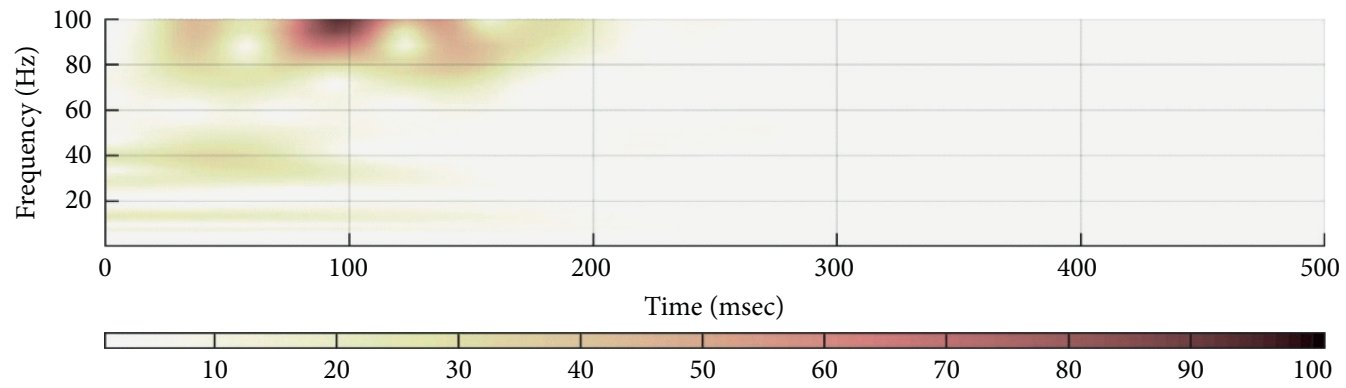

(c)

FigURE 14: $Y$ component of recorded near-source seismic ground motion in Bielszowice coal mine from blasting on 2020-08-16 with charge weight $192 \mathrm{~kg}$ and estimated seismic energy $2 * 10^{5}(\mathrm{~J})$. (a) Velocity seismogram (m/s); (b) amplitude Fourier spectrum; (c) continuous wavelet transform.

seismic signal. We have also shown in Figure 18. The 3D particle velocity ground motion that represents the $3 \mathrm{D}$ movement of the particles in the rock mass nearby the installed seismic probe. Opposite to the recorded vibration from the seismic event in Rydultowy coal mine, one can easily observe that this $3 \mathrm{D}$ motion has no dominant direction and is characteristic to the particle motion movement of explosive source mechanism.

Figures 13-15 present the recorded velocity seismograms of the triaxial geophone probe at the distance of $162 \mathrm{~m}$ from blasting on 2020-08-16 with charge weight $192 \mathrm{~kg}$ and estimated seismic energy $2 * 10^{5}(\mathrm{~J})$ in the Bielszowice coal 


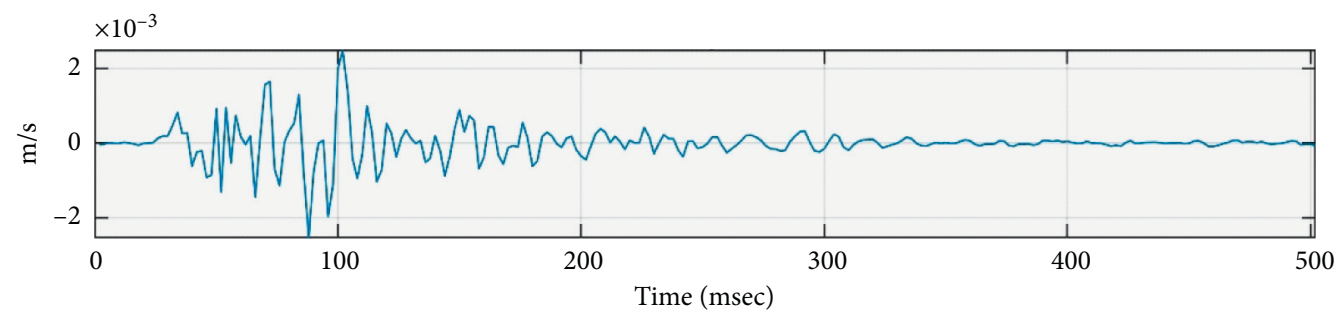

(a)

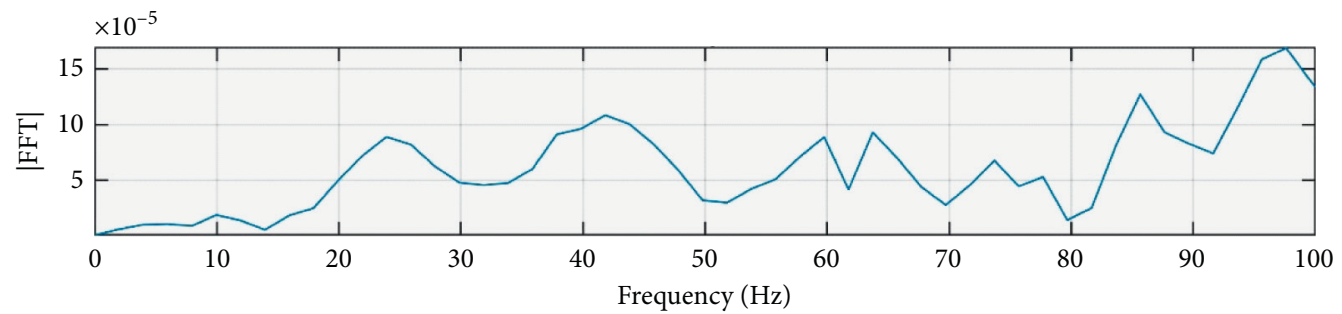

(b)

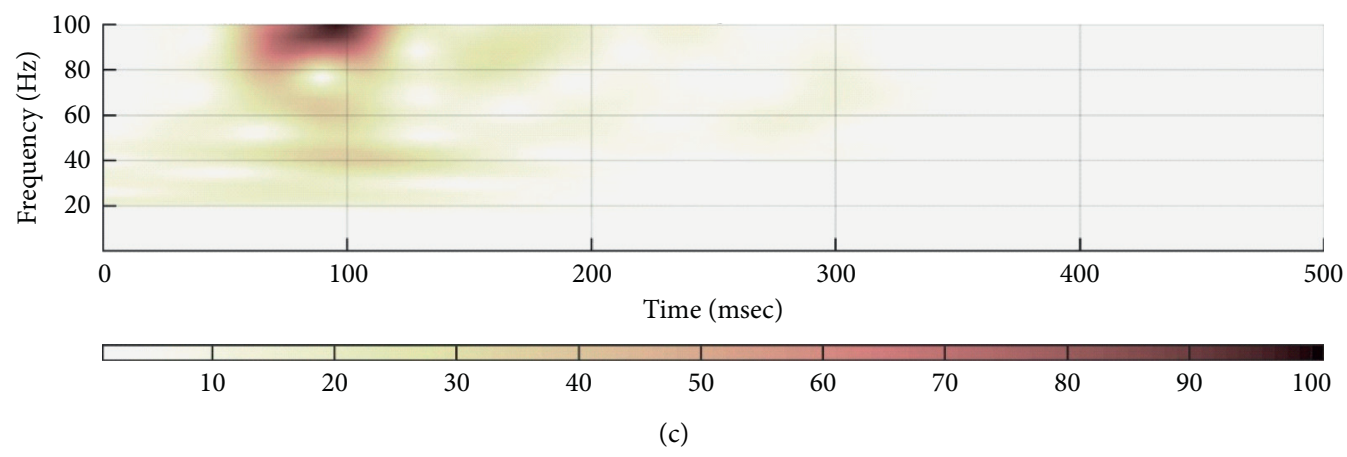

FIGURE 15: $Z$ component of recorded near-source seismic ground motion in Bielszowice coal mine from blasting on 2020-08-16 with charge weight $192 \mathrm{~kg}$ and estimated seismic energy $2 * 10^{5}(\mathrm{~J})$. (a) Velocity seismogram (m/s); (b) amplitude Fourier spectrum; (c) continuous wavelet transform.

mine. The PPV values for $X, Y$, and $Z$ components are $7 \mathrm{~mm} /$ $\mathrm{s}, 4.3 \mathrm{~mm} / \mathrm{s}$, and $2.5 \mathrm{~mm} / \mathrm{s}$, respectively, and the $\mathrm{PPV}$ value for the full $X Y Z$ vector is $7.2 \mathrm{~mm} / \mathrm{s}$. The calculated amplitude Fourier spectra for $X$ and $Z$ components have clearly visible dominant frequencies between $20 \mathrm{~Hz}$ and $100 \mathrm{~Hz}$, whereas there is an additional visible frequency band in the range $1 \mathrm{~Hz}-20 \mathrm{~Hz}$ for $Y$ component. More detailed time-frequency information is obtained from the continuous wavelet transform (CWT), where the dominant frequency group in the range $80 \mathrm{~Hz}-100 \mathrm{~Hz}$ is only visible for $Y$ and $Z$ components in separate time intervals. Comparing the calculated $X, Y$, and $Z$ CWT spectrograms with CWT spectrograms obtained for two analyzed seismic events, one can easily notice that the dominant frequency bands have been shifted towards higher frequencies. From the assessment of underground working stability point of view, this is an advantageous effect. The lower $20-40 \mathrm{~Hz}$ group of frequencies on the CWT spectrograms is visible on all three components but is not clearly dominant as opposed to higher frequencies. We also show in Figure 19 the 3D particle velocity ground motion that represents the $3 \mathrm{D}$ movement of the particles in the rock mass nearby the installed seismic probe. Opposite to the recorded vibration from the seismic event in Bielszowice coal mine, one can easily observe that this $3 \mathrm{D}$ motion has no dominant direction and is characteristic to the particle motion movement of explosive source mechanism.

All of the four triaxial strong motion velocity amplitude recordings have had the PPV value for the full $X Y Z$ vector greater or near the threshold value of $5 \mathrm{~mm} / \mathrm{s}$. Comparing these values with the constant lines of estimated PPV values in Figure 1, where all documented rockburst accidents in Upper Silesian Coal Basin, Poland, in the years 1988-2006 have been shown as a function of the distance from the damaged working R ( $\mathrm{m}$ ) and seismic energy Es (J), we can conclude, imprecisely, that all of the four analyzed seismic sources could pose a danger to underground mining workings. This result, however, cannot be overestimated for several reasons. First, we need to emphasize that even if there is an observation of high PPV value, it only indicates that the rockburst or damage of the excavation can occur. The higher the PPV value we have, the higher the probability of working damage is. However, there are many cases observed where high PPV values will not cause any damage to underground galleries. This does not indicate that the PPV criterion is incorrect but clearly shows that the damage to underground workings depends also on other factors: related to mining and 


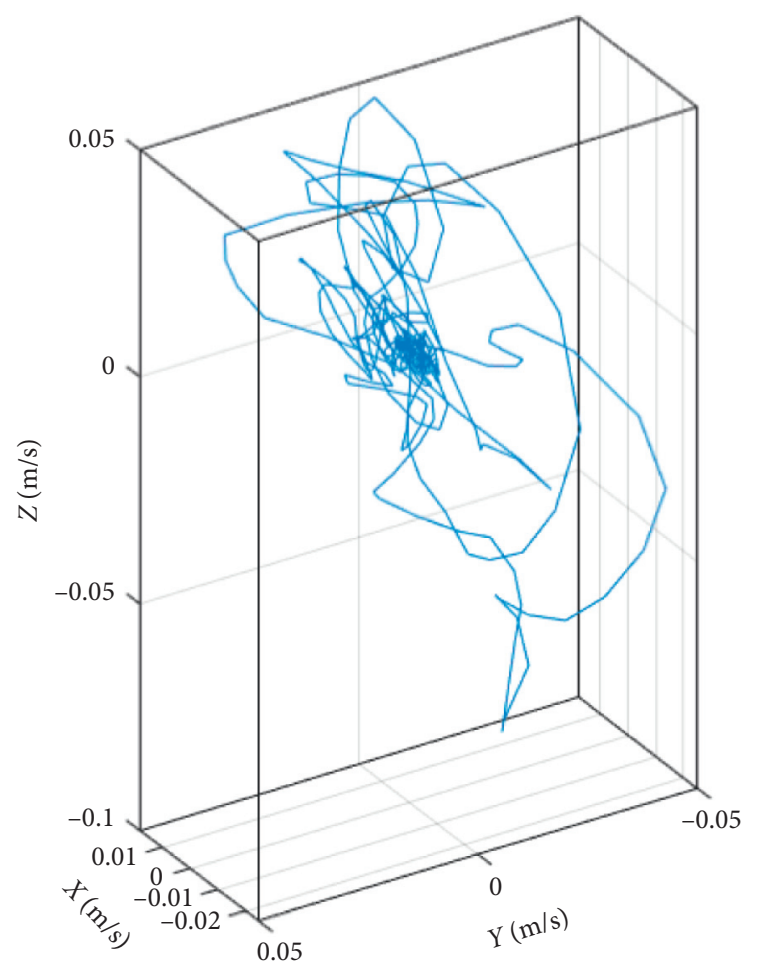

Figure 16: Recorded 3D particle velocity ground motion $(\mathrm{m} / \mathrm{s})$ in Rydultowy coal mine from seismic event that occurred on 2020-0721 with seismic energy $2 * 10^{8}(\mathrm{~J})$.

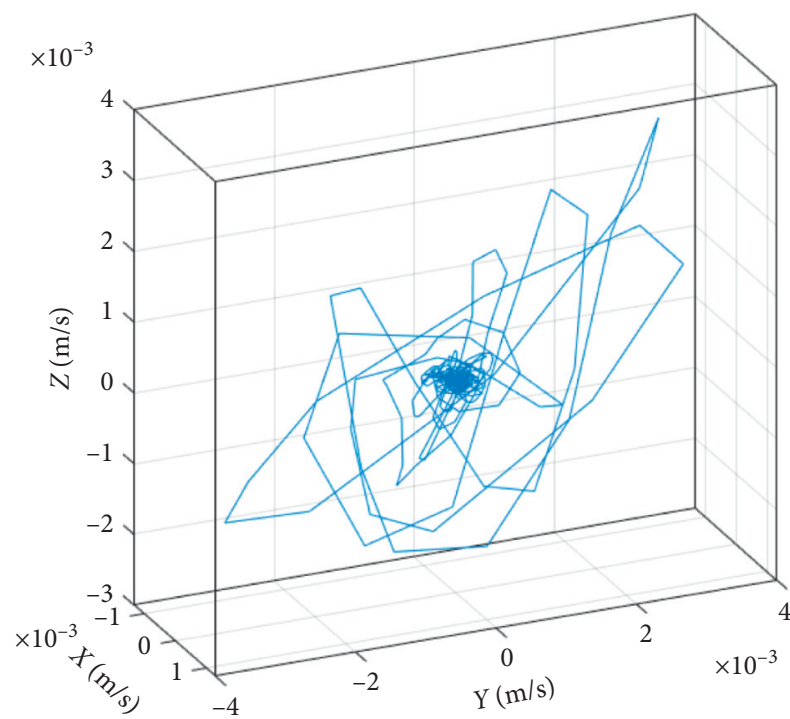

FIGURE 17: Recorded 3D particle velocity ground motion $(\mathrm{m} / \mathrm{s})$ in Rydultowy coal mine from blasting on 2020-07-25 with charge weight $72 \mathrm{~kg}$ and estimated seismic energy $8 * 10^{4}(\mathrm{~J})$.

geological conditions and properties of the rock mass and related to properties of the recorded seismic signal itself. It is well known that lower dominant frequencies of the recorded seismic signals are more damaging to the underground workings than higher ones, which is shown in the amplitude Fourier spectra of our signals. Nevertheless, we have also

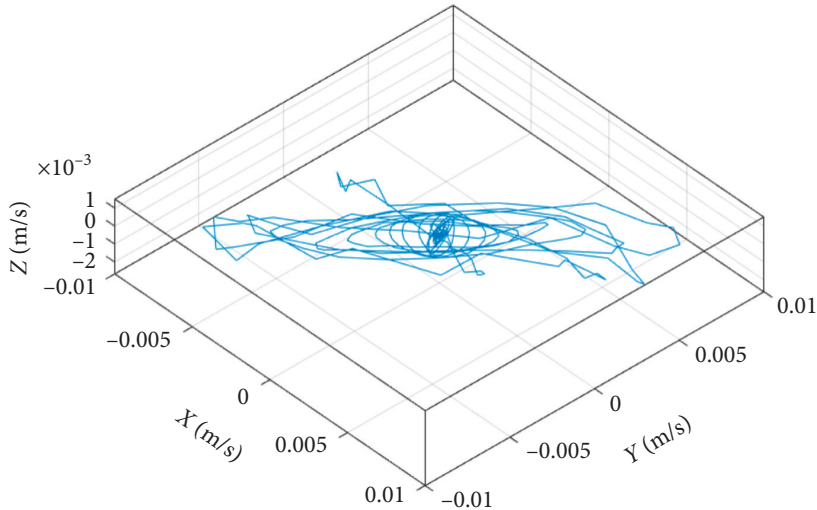

FIGURE 18: Recorded 3D particle velocity ground motion $(\mathrm{m} / \mathrm{s})$ in Bielszowice coal mine from seismic event that occurred on 2020$10-23$ with seismic energy $5 * 10^{5}(\mathrm{~J})$.

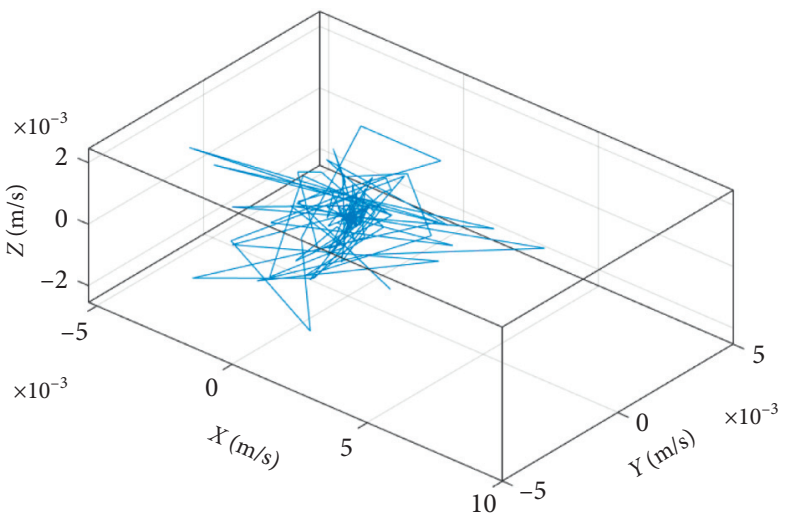

FIGURE 19: Recorded 3D particle velocity ground motion $(\mathrm{m} / \mathrm{s})$ in Bielszowice coal mine from blasting on 2020-08-16 with charge weight $192 \mathrm{~kg}$ and estimated seismic energy $2 * 10^{5}(\mathrm{~J})$.

indicated that further properties of strong motion seismic signals can be extracted with the use of CWT spectrograms showing the duration time of each frequency group. The longer the duration time of the lower frequency group is on the CWT spectrogram, the more the damaging effect on underground mining excavations can be observed. From that point of view, the recorded strong velocity ground motion in Rydultowy coal mine from a seismic event that occurred on 2020-07-21 with seismic energy $2 * 10^{8}(\mathrm{~J})$ has had the largest potential impact on underground mining working stability.

\section{Conclusions}

Selected recordings of near-source seismic ground motion of two high energy seismic events and two underground blasts were analyzed, indicating the importance of the dominant frequency band and its time duration in the assessment of underground mine working stability. The presented approach made it possible to compare two types of near-source seismic vibration generated by seismic events and by blasting. It was found that the spectral Fourier analysis of presented seismic signals may be insufficient due to the fact that they are highly nonstationary stochastic processes. Therefore, further analysis 
is required that incorporates both time and frequency domains to obtain a more credible assessment of the damaging effect on underground mine workings.

In the presented approach, time-frequency analysis was applied to the recorded strong motion seismic signals utilizing high resolution continuous wavelet transform (CWT) spectrograms. It was found that there are varying bandwidths of dominant frequencies in separate time intervals for the analyzed seismic signals, having significantly different influence on the potentially damaging effect on underground mining excavations. The CWT spectrogram analysis confirmed the known observation that seismic signals generated by blasts have significantly lower damaging effect on excavations comparing to seismic signals generated by high energy seismic events due to the existence of higher dominant frequencies in separate time intervals for seismic vibrations generated by blasts.

The analysis of $3 \mathrm{D}$ particle velocity ground motion that represents the 3D movement of the particles in the rock mass nearby the installed seismic probes indicates two significantly different spatial motions. First, for the analyzed seismic signals generated by strong seismic events, one dominant direction has been found and is characteristic to particle motion movement for fault slip source mechanisms. Second, for the analyzed seismic signals generated by blasting works, no dominant direction was detected, which is characteristic to particle motion movement for explosive source mechanisms.

\section{Data Availability}

The data are not freely available. Access to data is restricted because the data include information of related safety issues and current mining operations. The mining company that allowed us to publish the results does not wish to provide raw data.

\section{Disclosure}

Part of this research was carried out within the EPOS-PL project, European Plate Observing System.

\section{Conflicts of Interest}

The authors declare no conflicts of interest.

\section{Acknowledgments}

Part of this research was carried out within the EPOS-PL project, European Plate Observing System POIR.04.02.0014-A003/16, funded by the Operational Programme Smart Growth 2014-2020 (Priority IV: Increasing the Research Potential, Action 4.2: Development of Modern Research Infrastructure of the Science Sector), and cofinanced by European Regional Development Fund.

\section{References}

[1] C. H. Dowding, C. T. Aimone-Martin, B. M. Meins, and E. Hamdi, "Large structure response to high frequency excitation from rock blasting," International Journal of Rock Mechanics and Mining Sciences, vol. 111, pp. 54-63, 2018.

[2] R. Madariaga, "Seismic source theory," in Treatise on Geophysics, G. Schubert, Ed., vol. 4pp. 51-71, Elsevier, Amsterdam, Netherlands, 2nd edition, 2015.

[3] J. Dubiński and G. Mutke, "Characteristics of mining tremors within the near-wave field zone," in Induced Seismic Events. Pageoph Topical Volumes, P. Knoll and G. Kowalle, Eds., pp. 249-261, Birkhäuser Basel, 1996.

[4] W. Zhang, N. Ma, J. Ren, and C. Li, "Peak particle velocity of vibration events in underground coal mine and their caused stress increment," Measurement, vol. 169, Article ID 108520, 2021.

[5] J. Feng, E. Wang, H. Ding, Q. Huang, and X. Chen, "Deterministic seismic hazard assessment of coal fractures in underground coal mine: a case study," Soil Dynamics and Earthquake Engineering, vol. 129, Article ID 105921, 2020.

[6] G. Mutke, "Ground motion associated with coal mine tremors close to the underground openings," in Proceedings of the joint Japan-Poland Symposium on Mining and Experimental Seismology, J. Kyoto, Y. Ogasawara, and Ando, Eds., Balkema Publishers, Kyoto, Japan, pp. 91-102, November 1999.

[7] AG. Butler and G. Van Aswegen, "Ground velocity relationships based on a large sample of underground measurements in two South African mining regions," in Proceedings of the Rockburst And Seismicity In Mines, pp. 41-49, Balkema, Young, Kingston, Ontario, August 1993.

[8] G. Mutke, W. Masny, and S. Prusek, "Peak particle velocity as an indicator of dynamic load exerted on the support of underground workings," Acta Geodynamica et Geomaterialia, vol. 13, no. 4, pp. 367-378, 2016.

[9] G. Mutke, "Characteristics of near-field ground motion resulting from mining tremors to assessing of rock bursts hazard," GIG's Scientific Works, vol. 87, 2007 in Polish.

[10] A. McGarr, R. W. E. Green, and S. M. Spottiswoode, "Strong ground motion of mine tremors: some implications for nearsource ground motion parameters," Bulletin of the Seismological Society of America, vol. 71, no. 1, pp. 295-319, 1981.

[11] J. He, L.-M. Dou, W. Cai, Z.-L. Li, and Y.-L. Ding, "In situ test study of characteristics of coal mining dynamic load," Shock and Vibration, vol. 2015, Article ID 121053, 8 pages, 2015.

[12] J. Silva, T. Worsey, and B. Lusk, "Practical assessment of rock damage due to blasting," International Journal of Mining Science and Technology, vol. 29, no. 3, pp. 379-385, 2019.

[13] H. Bakhshandeh Amnieh, A. Siamaki, and S. Soltani, "Design of blasting pattern in proportion to the peak particle velocity (PPV): artificial neural networks approach," Safety Science, vol. 50, no. 9, pp. 1913-1916, 2012.

[14] H. Dehghani and M. Ataee-pour, "Development of a model to predict peak particle velocity in a blasting operation," International Journal of Rock Mechanics and Mining Sciences, vol. 48, no. 1, pp. 51-58, 2011.

[15] Z.-1. Li, L.-m. Dou, G.-f. Wang, W. Cai, J. He, and Y.-l. Ding, "Risk evaluation of rock burst through theory of static and dynamic stresses superposition," Journal of Central South University, vol. 22, no. 2, pp. 676-683, 2015.

[16] J. He, L. Dou, S. Gong, J. Li, and Z. Ma, "Rock burst assessment and prediction by dynamic and static stress analysis based on micro-seismic monitoring," International Journal of Rock Mechanics and Mining Sciences, vol. 93, pp. 46-53, 2017.

[17] G. P. Mavroeidis and A. Papageorgiou, "A mathematical representation of near-fault ground motions," Bulletin of the Seismological Society of America, vol. 93, no. 3, pp. 1099-1131, 2003. 
[18] J. W. Baker, "Quantitative classification of near-fault ground motions using wavelet analysis," Bulletin of the Seismological Society of America, vol. 97, no. 5, pp. 1486-1501, 2007.

[19] J. D. Bray and A. Rodriguez-Marek, "Characterization of forward-directivity ground motions in the near-fault region," Soil Dynamics and Earthquake Engineering, vol. 24, no. 11, pp. 815-828, 2004.

[20] T. G. Cork, J. H. Kim, G. P. Mavroeidis, J. K. Kim, B. Halldorsson, and A. S. Papageorgiou, "Effects of tectonic regime and soil conditions on the pulse period of near-fault ground motions," Soil Dynamics and Earthquake Engineering, vol. 80, pp. 102-118, 2016.

[21] P. G. Somerville, "Magnitude scaling of the near fault rupture directivity pulse," Physics of the Earth and Planetary Interiors, vol. 137, no. 1-4, pp. 201-212, 2003.

[22] C. H. Dowding, Blast Vibration Monitoring and Control, Prentice-Hall, Englewood Cliffs, 1985.

[23] S. C. Olhede and A. T. Walden, "Generalized morse wavelets," IEEE Transactions on Signal Processing, vol. 50, no. 11, pp. 2661-2670, 2002.

[24] T. O. Hagan, A. Milev, S. Spottiswoode, and M. Hildyard, "Simulated rockburst experiment - an overview," Journal of the South African Institute of Mining and Metallurgy, vol. 101, no. 5, pp. 217-222, 2001. 